Publicación semestral. ISSN 2215-4906

Volumen 80 - Número 1

Julio - Diciembre 2020

\title{
Reflejos del retrato femenino pictórico: la necesidad de una imagen transformadora en México
}

\author{
Reflections of the pictorial female portrait: the need for a \\ transformative image in Mexico
}

Gabriela Arhelí García Guerra

Ioulia Akhmadeeva

\section{(c) (i) $(\mathrm{E})$}

Esta obra está bajo una licencia Creative Commons

Reconocimiento-No comercial-Sin Obra Derivada 
Artículo

\title{
Reflejos del retrato femenino pictórico: la necesidad de una imagen transformadora en México
}

\author{
Reflections of the pictorial female portrait: the need for a \\ transformative image in Mexico
}

\author{
Gabriela Arhelí García Guerra ${ }^{1}$ \\ Universidad Autónoma de Chihuahua \\ México \\ Ioulia Akhmadeeva ${ }^{2}$ \\ Universidad Michoacana de San Nicolás de Hildalgo \\ México
}

Recibido: 09 de setiembre de 2019 Aprobado: 04 de noviembre de 2019

\begin{abstract}
Resumen
El retrato artístico y el feminismo en la actualidad transgreden las barreras sociales, utilizan la teoría y la práctica para realizar propuestas con el fin de deconstruir normas y costumbres, con base en las necesidades de su espacio y tiempo. De tal manera, las obras realizadas bajo esta perspectiva, en el siglo XXI, buscan la ruptura de los paradigmas y visibilizar las imposiciones androcéntricas, eurocéntricas y obsoletas. Por ello, el presente trabajo utiliza el análisis de la imagen a través de la noción del espejo relacionada a trabajos teóricos y análisis de dos pinturas hechas por artistas mexicanas contemporáneas. Se busca reflexionar por medio de bases teóricas sobre cómo estas obras permiten visibilizar el entorno como un reflejo de la sociedad a la cual pertenecen. Finalmente, se cuestiona los efectos de lo concebido por retrato femenino y feminismo.
\end{abstract}

Palabras clave: retrato; femenino; feminismo; pintura; arte; siglo XXI.

1 Estudiante de tercer semestre en el Doctorado en Educación Artes y Humanidades en la Universidad Autónoma de Chihuahua. Becaria del Consejo Nacional de Ciencia y Tecnología (CONACYT). ORCID: 0000-0002-3339-1840. Correo electrónico gagabyneta@gmail.com

2 Profesora e Investigadora de la Facultad de Bellas Artes de la Universidad Michoacana de San Nicolás de Hidalgo, con perfil PROMEP y forma parte del núcleo académico básico del Doctorado Interinstitucional de Arte y Cultura (DIAC). Correo electrónico: loulia.akh@gmail.com

ESCENA. Revista de las artes, 2020, Vol. 80, Núm. 1, pp. 138-147 ISSN 2215-4906 
Reflejos del retrato femenino pictórico: la necesidad de una imagen

Artículo transformadora en México

\begin{abstract}
Today the artistic portrait and feminism transgress social barriers, they use theory and practice to make proposals in order to deconstruct norms and customs, based on the needs of their space and time. Thus, the works carried out under this perspective in the 21 st century seek to break the paradigms and make visible the androcentric, Eurocentric and obsolete impositions. Therefore, this work uses the analysis of the image through the notion of the mirror related to theoretical works of two paintings made by contemporary Mexican artists. It seeks to reflect through theoretical bases on how these works make visible the environment as a reflection of the society to which they belong. Finally, is questioned the effects of the conceived by feminine portrait and feminism.
\end{abstract}

Keywords: female; portrait; feminism; painting; art; 21st century 


\section{Introducción}

Las cuestiones artísticas se dedican a observar el mundo para representarlo, por tanto, se puede asumir que el arte colabora en generar un pensamiento crítico en la sociedad al asimilar la complejidad en la realidad. Sin embargo, cuando la mayoría de las creaciones realizadas pertenecen a un grupo social específico significa que hay una ausencia de visión del entorno. Un ejemplo de esto es la difusión y trascendencia en la historia del arte de creadores masculinos occidentales y, en consecuencia, la subyugación de creaciones procedentes de otro espacio geográfico, de otro género o incluso de diferente estilo artístico. De tal manera, el presente texto se concentra en obras contemporáneas que abordan las problemáticas desde una visión femenina. Por un lado, en Latinoamérica la cantidad de creadoras dentro de los museos y galerías es significantemente menor a la de los hombres creadores, lo cual es pertinente mencionar, precisamente, por la necesidad de repensar las ideas sobre el arte y la perspectiva en la cual se crea la imagen. Por otro lado, los aspectos técnicos en el arte sufren constantemente una reconfiguración. Los medios tecnológicos y la innovación de materiales son las propuestas más originales, en algunos casos, también son las más efímeras. Quizá estas características propician la poca producción o noticia de los medios tradicionales como la pintura, grabado o escultura. De acuerdo con Alario (2008):

Las formas de representación, los límites y la presencia del cuerpo en las obras feministas han sido desde la década de 1970, y aún siguen siéndolo, algunos de los elementos polémicos. Estas, junto con el papel prioritario que ha adquirido el tema de la identidad o las identidades, y la proliferación de nuevas técnicas y soportes que ha caracterizado a la producción artística de las mujeres en las últimas décadas. (p. 203)

A pesar de los nuevos medios de creación, artistas como Marianela de la Hoz, Mónica Castillo, Ana Teresa Fernández, Rocío Caballero, Marisa Polín, entre otras, forman parte de algunas de las más nombradas pintoras en México. Ellas ponen en alto la creación tradicional del arte y generan propuestas visuales con temáticas vigentes en sus obras. Además, estas pintoras abordan la creación de tal modo que evidencian cómo la realidad plasmada en el arte es más compleja que la mimesis del prototipo de belleza. Los propósitos de este texto se enfocan en el análisis de la figura femenina representada a partir de dos obras, la primera de Marianela de la Hoz y la segunda de Rocío Caballero. En ambas se muestra el panorama y enfoque sociopolítico de México con un tono crítico, lo cual, a su vez, es un primer paso ante la necesidad de transformación desde la imagen femenina. Asimismo, se busca visibilizar la poca difusión de pinturas realizadas por mujeres tanto en los medios de comunicación como en instancias culturales de trabajos a pesar de la variedad de propuestas actuales en el arte. Ya en el siglo XX ocurrió un escenario semejante en donde se ignoró la producción femenina, de las pintoras y muralistas, entre ellas se encuentran María Izquierdo, Aurora Reyes, Olga 
Reflejos del retrato femenino pictórico: la necesidad de una imagen

Artículo transformadora en México

Costa, Fanny Rabel y Remedios Varo. De acuerdo con Comisarenco (2017) en esa época existía un monopolio integrado "por Rivera, Orozco y Siqueiros" (p. 64). En consecuencia, para que cambie la estructura del rol de la mujer en la sociedad, la visión artística, la concepción del arte y la imagen femenina es necesario darles voz a las personas con menos privilegios en este medio. Irónicamente, a pesar de que la equidad de género y el feminismo son temas populares en la cotidianidad, existe muy poca difusión de obras generadas por estas mujeres, y el contenido relacionado a su desigualdad.

La representación de la figura femenina se ha transformado según el contexto de cada época y los propósitos del arte. No obstante, la necesidad de expresar y de canalizar emociones del ser humano por medio de las obras de arte posibilita a los creadores jugar con sus conocimientos y percepciones para generar nuevas realidades. Ello permite al artista proponer una transformación de su entorno o señalar aquellas prácticas que entiende equivocadas. De tal manera, las obras muestran el continuo cambio de la percepción sobre las cosas y, además, son consecuencia del sistema de vida del creador. Bajo la premisa de que no se puede separar al creador de su contexto histórico, otro de los objetivos es señalar la paradoja del retrato a través de la metáfora del espejo de acuerdo con Baudrillard, Burke y Eco.

\section{La complejidad reflejada en el retrato femenino}

El registro de los rostros, cuerpos y acciones cotidianas nos muestran la interpretación e interacción entre el mundo y el ser humano. En el retrato se representa la ancestral necesidad de permanencia y trascendencia. En este se encuentra el reflejo de lo social, se plasma la memoria del ser humano, se encuentran proyectadas las tradiciones, los valores y la moral de su momento. A pesar de que el retrato se concentra en un individuo particular, el creador es quien coloca una carga política o una crítica en su obra. Asimismo, este género artístico ha prevalecido por dejar una huella que traspasa barreras temporales y por su capacidad de ofrecer un mensaje. En el retrato, se pueden exaltar banalidades, ya que se enfatiza para ridiculizar o criticar. Pope-Hennessy hace referencia al retrato atemporal, el cual permite al espectador verse reflejado e interpretar "un problema que todos nosotros podemos concebir con independencia del contexto temporal en que se produzca" (1985, p. 9). Por otro lado, Read (1963) definió así: "En los mejores retratos, el pintor o el escultor va más allá del carácter personal de su modelo y llega a ciertas implicaciones universales" (p. 27). En conjunto, el retrato logra la trascendencia de la memoria de una persona, da un estatus social, dignifica, satiriza o simplemente imita de manera realista a un ser. En relación con lo anterior, la autora Martínez-Artero (2004) menciona: "un retrato es la representación de un sujeto... atendiendo principalmente a la idea de sujeto, es decir, como se muestra el individuo particular" (p. 11).

ESCENA. Revista de las artes, 2020, Vol. 80, Núm. 1 (julio-diciembre), pp. 138-147 
El arte, condicionado por el ser humano, retrata la sociedad, captura lo obvio y lo latente sin ser este su principal propósito. Las obras son, además, la manifestación del pensamiento individual. Del mismo modo, las imágenes femeninas en los medios de comunicación contienen prototipos occidentales, por lo que fomentan expectativas sobre un estilo de vida, una apariencia física y un comportamiento ideal. Estas representaciones discriminan todo aquello que no asemeja a estos cánones. Por ello, es importante señalar que cada espacio geográfico tiene sus propias economías, creencias y características fisionómicas.

A pesar de lo mencionado anteriormente, el retrato se convierte en una aporía al buscar representar un contenido universal por medio de las características particulares de un sujeto. No obstante, cuando se trata de la figura de la mujer existe un prototipo con una visión muy limitada, la cual propone una inferioridad de manera latente. Con lo anterior, nos referimos a las construcciones de género, las cuales simplifican banalmente el ser mujer u hombre y con ello no permiten su desarrollo en áreas que están dentro del género opuesto. Según Morin (1990): "La incapacidad para concebir la complejidad de la realidad antropo-social, en su micro-dimensión (el ser individual) y en su macro-dimensión (el conjunte planetario de la humanidad), ha conducido a infinitas tragedias y nos condujo a la tragedia suprema" (p. 17).

Para complementar lo anterior, es necesario señalar algunas maneras de significar por medio de metáforas y conceptos, los cuales refuerzan el sentido de las obras. Por un lado, en las pinturas se representa el rol, la identidad y la individualidad. Es decir, el sujeto representado tiene una carga en diferentes aspectos, lo cual permite al espectador comprender el papel del retratado, los vínculos que le pueden dar poder o menor rango social, el contexto y, por tanto, la idea de moral de su momento. Mandoki (2008) nos facilita la identificación de esto y explica:

Mientras la identidad es personal y específica, el rol es anónimo y general; la identidad se construye mientras el rol se asume; en la identidad el sujeto es activo, mientras en el rol es relativamente pasivo. Por identidades vamos a entender a las familiares, religiosas, escolares, nacionales profesionales, entre otras. En cuanto a que sean construidas personal y colectivamente involucran una intencionalidad. (p. 78)

Por otro lado, la noción del espejo, a partir de distintos teóricos, ayuda a relacionar la alegoría y la realidad. En relación con esto, se encuentra la propuesta de Baudrillard (1969) quien vincula el espejo y el retrato. El autor se aproxima a explicar uno de los propósitos del género retratístico a partir de una comparación de la obra artística con un objeto en donde la burguesía "encuentra el privilegio de multiplicar su apariencia y de jugar con sus bienes" (p. 21). Tanto el espejo como el retrato tienen un contenido más allá de la imagen proyectada, que sirve para "el desarrollo histórico de la conciencia individual" (p. 21). Asimismo, Burke (2005) hace referencia al retrato como espejo y forma simbólica. Sin embargo, al contrario de Baudrillard, al correlacionarlo con el espejo y su proyección hace énfasis en una 
Reflejos del retrato femenino pictórico: la necesidad de una imagen

Artículo transformadora en México

distorsión de la realidad, lo cual significa que no se está plasmando una verdad en las obras. Incluso, menciona que ni siquiera las fotografías capturan la realidad, sin embargo, los retratos artísticos son declaraciones subjetivas de determinados hechos (p. 37). De ese modo, señala:

A cierto nivel, pues, las imágenes son una fuente poco fiable, un espejo deformante. Pero compensan esa desventaja proporcionando buenos testimonios a otro nivel... Las imágenes son traicioneras porque el arte tiene sus propias convenciones, porque sigue una línea de desarrollo interno y al mismo tiempo reacciona frente al mundo exterior. (Burke, 2005, p. 38)

Burke entiende la obra artística como un registro material de la percepción del creador, nos hace conscientes de la alteración de la "realidad" debido a la perspectiva y no entiende la obra como una verdad absoluta, por esta razón, se refiere a ello como distorsión. Bajo esta misma metáfora, Eco (2012) menciona: "el espejo, en el mundo de los signos, se convierte en el fantasma de sí mismo, caricatura, irrisión, recuerdo" (p. 41). Es decir, las proyecciones del ser en la obra son, de alguna manera, fragmentos del representado. Así, para exaltar una característica del modelo es posible transformar un aspecto específico, ya sea parte del cuerpo, vestimenta o entorno para diferenciarlo. Eco alude a los espejos deformantes que aproximan a la risa y a las emociones delirantes con las que, a veces, algunas partes del cuerpo se alargan o se acortan y remiten a los espejos de circo o lugares infantiles. Por otro lado, el mismo autor también nos conduce hacia una posible crítica sobre la mimesis del sujeto en las obras, "en el caso de los espejos no hay imagen más verdadera que los originales. Lo catóptrico, capaz de reflejar (sin modificarlo) lo semiótico que existe fuera de él, no puede ser es 'reflejado' por lo semiósico" (Eco, 2012, p. 41).

Imagen 1. Calladitas. Huevo y tempera

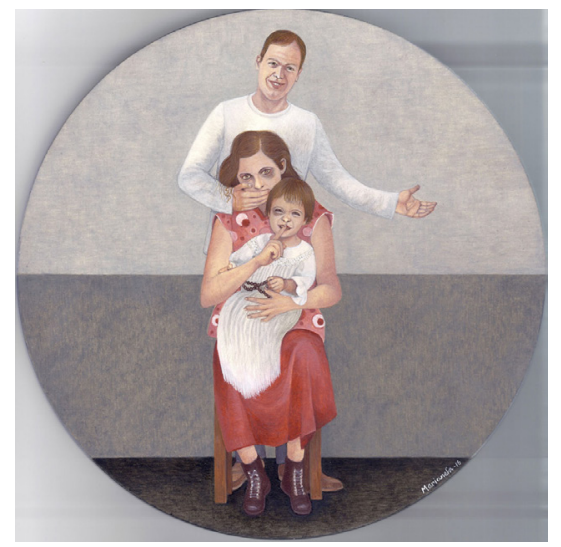

Fuente: Marianela de la Hoz, 2016.
Se entiende entonces, a partir de lo anterior, cómo las cuestiones técnicas le permiten al autor otorgarles una aportación visual y conceptual a las obras. Es decir, en un retrato es posible la repetición de la imagen, sin embargo, no es este el único propósito de las obras. La investigadora en historia del arte, Andrea Giunta (2018) explica como: "un retrato en el que, más importantes que la aparición de su rostro, son los mapas de experiencias personales y culturales que cruzan su biografía" (párr. 21). En el caso particular de la obra Calladitas, realizada por Marianela de la Hoz, (Imagen 1) es intencional el representar una problemática en su obra. En ella nos muestra los estragos de la violencia familiar inculcada desde una perspectiva machista, la cual propone que la mujer debe de ser sumisa y aceptar los actos del hombre por este ser el "jefe" del 
hogar. Este tipo de violencia, como bien se ve en la imagen, es inculcada por generaciones y se aprende en el contexto familiar. De tal manera, Marianela de la Hoz nos muestra tal cual un espejo, aquello que se vive en un hogar que tolera la violencia doméstica. Por tanto, para comprender este tipo de imágenes proyectadas resulta prudente la metáfora de los espejos, ya que capturan -en este caso- las esencias del retrato familiar, mas no simplifican con una imagen sus vidas.

También, sobre la definición de las personas más allá de los constructos sociales, se ha visibilizado que no necesariamente todo es binario. Erradicar este pensamiento permite apreciar a las personas por su condición humana y no por su género. Por esto, por ejemplo, designarle a la mujer el rosa y al hombre el azul es un pensamiento que debe ser rebasado: "la estrategia política requiere al conocimiento complejo, porque la estrategia surge trabajando con y contra lo incierto, lo aleatorio, el juego múltiple de las interacciones y las retroacciones" (Morin, 1990, p. 17). En consecuencia, los retratos con cargas feministas contribuyen a desmitificar preconcepciones. Asimismo, complejizan el panorama del espectador por su aporte en cuanto a discursos de género en sus piezas artísticas.

En México existe una riqueza cultural difícil de ocultar, a pesar de los intentos de opacarla y menospreciarla a través de la desigualdad y violencia de género. Es, precisamente, el papel del arte mostrar aquello incómodo, olvidado o sin voz. Según Alario: "los cuerpos de mujer que se nos presentan son resultado de una cierta tiranía de la invisibilidad" (2008, p. 204). Hay un largo camino por recorrer en México y Latinoamérica, no obstante, ya existen trabajos importantes como los de la teórica Silvia Cusicanqui (2010), quien menciona:

No puede haber un discurso de la descolonización, una teoría de la descolonización, sin una práctica descolonizadora. El discurso del multiculturalismo y el discurso de la hibridez son lecturas esencialistas e historicistas de la cuestión indígena, que no tocan los temas de fondo de la descolonización; antes bien, encubren y renuevan prácticas efectivas de colonización y subalternización. (p. 62)

De tal manera, como dice Cusicanqui, no basta con los discursos, sino con prácticas distintas para la inclusión y justicia. En este texto se mencionó, principalmente, a la mujer mexicana promedio, sin embargo, también es importante mencionar a la mujer indígena y con escasos recursos, ya que son ellas quienes cuentan con menos voz y tienen más necesidad de ser escuchadas. En consecuencia, es importante mencionar ejemplos de obras con discursos feministas que deconstruyen la concepción sobre la mujer, el arte y el creador. De algún modo, Rocío Caballero con su pintura Los sueños rotos (2009) lleva la problemática de los feminicidios a un nivel internacional, al presionar a la justicia del país por medio de la difusión de tales hechos, los cuales afectan, principalmente en México, a las mujeres mestizas de escasos recursos. La pintura de Rocío Caballero muestra a una mujer vestida de novia con un velo casi 
transparente que cubre la mitad de dos cruces rosas. Las cruces particularmente simbolizan una realidad de crímenes contra las mujeres en México. Su vestido como una telaraña alude a cómo la mujer está atrapada por su propio género. La retratada se ubica en un espacio exterior con la luz del atardecer, nubes moradas, rosas y naranjas. Caballero hace alusión a las expectativas y sueños interrumpidos de las víctimas de feminicidio en su pintura. De tal manera, a partir del simbolismo de su vestido y las figuras de papel con forma de niños que aparecen, se deduce como la mujer buscaba una vida estable con una familia, bajo la percepción de las imposiciones occidentales. Al realizar esta pintura, Caballero se sale de la comodidad del silencio y, tal como menciona Cusicanqui, transforma el discurso de protesta contra el feminicidio en la creación de esta imagen.

\section{Conclusión}

El espejo proyecta objetivamente un fragmento del espacio al cual pertenece. Aunque el sujeto manipule el ángulo de visión para favorecerlo, hay aspectos que son imposibles de ocultar. La analogía del espejo sirve para reflexionar sobre cómo los retratos de Castillo y De la Hoz señalan la violencia de género e impunidad en México. El retrato muestra emociones universales, las cuales, a partir de un rostro ajeno, paradójicamente, logran colocar al espectador en el lugar de la retratada, lo que crea vínculos a través de la reflexión y el análisis de la obra. De acuerdo con Morin (1990): "la dificultad del pensamiento complejo es que debe afrontar lo entramado (el juego infinito de inter-retroacciones), la solidaridad de los fenómenos entre sí, la bruma, la incertidumbre, la contradicción" (p. 18). De tal manera, este texto busca demostrar la aporía del sentido del retrato sin caer en una catalogación simplista y otorgándole una complejidad a la interpretación.

En conclusión, el arte está condicionado por intereses políticos, preconcepciones e ideologías. No obstante, en este ensayo se propone asumir el arte como un concepto abierto, ya que al igual que el pensamiento humano este se transforma y, por tanto, también transforma el retrato y la imagen femenina. Por ello, el antídoto para erradicar una visión limitada de los conceptos antes mencionados es desmitificar tanto la obra como el contenido. Lo anterior, no desmerita las producciones artísticas occidentales, ya que no se pueden negar las aportaciones conceptuales, visuales, históricas e incluso críticas que muchas de estas obras con figuras femeninas contienen. 


\section{Referencias}

Alario, T. (2008). Arte y feminismo. Aldamar, España: Editorial Nerea.

Baudrillard, J. (1969). El sistema de los objetos. París, Francia: Éditions Gallimard.

Burke, P. (2005). Visto y no visto: El uso de la imagen como documento histórico. Barcelona, España: Biblioteca Debolsillo. Recuperado de: http://rodolfogiunta.com. ar/Patrimonio/Biblio 032.pdf.

Comisarenco, D. (2017). Eclipse de siete lunas: Mujeres muralistas en México. Ciudad de México, México: Artes de México.

Cusicanqui, S. (2010). Ch'ixinakax utxiwa: una reflexión sobre prácticas y discursos descolonizadores. Buenos Aires, Argentina: Tinta Limón y Retazos.

Eco, U. (2012). De los espejos y otros ensayos. Barcelona, España: Debolsillo.

Giunta, A. (2018). Feminismo y arte latinoamericano: historias de artistas que emanciparon el cuerpo. Buenos Aires, Argentina: Siglo veintiuno editores.

Mandoki, K. (2008). Estética cotidiana y juegos de la cultura: prosaica I. Conaculta. D.F., México.

Martínez-Artero, R. (2004). El retrato: Del sujeto en el retrato. Barcelona, España: Montesinos.

Morin, E. (1990). Introducción al pensamiento complejo. D.F., México: Gedisa.

Pope-Hennessy, J. (1985). El retrato en el Renacimiento: conferencias sobre arte. Madrid, España: Akal.

Read, H. (1963). El significado del arte. Buenos Aires, Argentina: Editorial Proyección. 